\title{
Indirect Construction of Hedonic Price Indexes for Private Properties
}

\author{
STEFAN S. FAHRLÄNDER ${ }^{a}$
}

JEL-Classification: C31, R31

Keywords: Hedonic price, private property, direct index, indirect index

\section{Introduction}

Hedonic models have been widely used in Switzerland by mortgage lenders in day to day business for more than a decade. Although estimating today's market values, the companies compile an increasing number of "historic" transaction prices together with the characteristics of the private properties. These data allow analysis on the construction and estimation of price path of private properties in Switzerland.

For modelling the price paths several methods are used in the literature. Popular but little quality adjusted and therefore susceptible to biases is the indexation of mean or median prices of sold properties. Recommended are repeat sales methods, since the changes of the prices of identical properties are compared.' However the problems of ageing and the declining condition or the consideration of refurbishments remain a challenge. In addition, in markets like Switzerland with a low home ownership rate and a very small turnover rate of the properties the use of the repeat sales method is hardly possible since data is simply not available. ${ }^{2}$ Therefore the hedonic method is very popular and widely used in

a Fahrländer Partner AG, Uetlibergstrasse 20, 8045 Zürich, Switzerland, +41 43333 05 55; sf@ fpre.ch.

This paper benefited from helpful comments by Robert Leu, Dominik Matter, Klaus Neusser and the editors. The usual disclaimer applies. Special thanks to the data providing Swiss banks and insurance companies.

1 See for example Bender, Gacem and Hoesli (1994), Maurer, Pitzer and Sebastian (2000) or Wolverton and Senteza (2000).

2 As of the 2000 census the home ownership rate in Switzerland was at 34.6\%. Today's rate might be $38 \%$ to $39 \%$ and possibly increase to about $40 \%$ by 2010 (see BAK \& fpre 2007 , p. 12). 
the literature and in practice since it allows the description of a quality adjusted price path of properties using comparables.

For Switzerland several studies applying the direct hedonic method on private properties have been published in recent years, like the studies of SALvi, SchELlenbauer and Schmidt (2004), Scognamiglio (2000), Hoesli, Favarger and Giaccotto (1997), Bignasca et al. (1996) and Bender, Gacem and Hoesli (1994). ${ }^{3}$ These studies have in common the use of the direct hedonic method for the construction of price indexes, i.e. the pooling of the data over the entire observed period and the use of - regionally differentiated - dummy variables for the change of the index over time. The indirect method, that is, the estimation of hedonic models on a year to year basis and the indexation of the predicted values of properties is rarely used in the literature. ${ }^{4}$

The main difference between the two methods is that the hedonic prices are usually fixed when using the direct method whereas they are potentially variable when using the indirect method. In the direct method, the dummies for the period of the transaction are directly used for indexation whereas in the indirect method market values for properties are predicted for each period and the index is constructed based on these market values. For the indexation of an average property, the differences in the outcome are small, but for the indexation of nonaverage objects, direct indexes or indirect indexes based on pooled data and fixed hedonic prices might be biased if structural changes exist.

Some authors stress the superiority of the indirect method over the direct method since in the long term the hedonic prices should not be fixed both from a theoretical and an empirical point of view (see Maurer, Pitzer and Sebastian, 2000, p.4, and Murray and Sarantis, 1999).

The focus of this article is the construction and the discussion of indirect hedonic price indexes for condominium and single family houses in Switzerland and its regions.

For the period 1985 to 2004 data for 38803 transactions of condominiums as well as data for 30870 transactions of single family houses are available for this purpose. For each transaction, information on characteristics such as location, size, standard, year of construction are available (Section 2). The general setup

3 Bender, Gacem and Hoesli (1994) computed both direct and indirect hedonic indexes for the Swiss canton of Geneva and discussed their superiority over indexes based on average prices.

4 We constructed indirect hedonic indexes for private properties based on transaction prices but modelling the communal price levels with offer prices from properties advertised in newspapers (see Fahrländer, 2001a and 2001b and Fahrländer and Hausmann, 2001). Also see FAHRLÄNDER (2007). 
of the hedonic model and its nationwide generalization is discussed in FAHRLÄNDER (2006 and 2007). Basically the same setup is used for the index construction that is the focus of this article. ${ }^{5}$ Due to relatively small sample sizes it is not possible to estimate price levels for all of the Swiss villages and city districts for every year. Therefore the estimated price levels for the year 2004 are used as well as yearly and quarterly dummy variables for the dynamic development of the prices on a regional level. This leaves the sequence of the price levels constant within a region (Section 3.1).

We find that the hedonic prices change over time but the pooling over a short period is not a major problem. Indirect indexes should be applied for the longterm indexation of non-average properties since direct indexes can be biased (Section 3.2).

Using indirect index construction market values for a wide variety of properties all over Switzerland can be estimated over the period 1985 to 2004. The consideration of ageing and refurbishments are subject of Section 3.3, the regional dynamics of the Swiss markets for private properties are subject of Section 3.4. Section 4 concludes.

\section{Data}

The analysis is based on arm's length transactions of single family houses and condominiums all over Switzerland, which took place between 1985 and $2004{ }^{6}$ The data was compiled by Swiss banks and insurance companies in day-to-day business (data pool). ${ }^{7}$ Due to the wide range of participating companies, which cover different customer segments - i.e. banks covering retail and private banking, insurance companies and the "Alternative Bank"-, it is assumed that the available transaction-data widely represent the Swiss market and most of its regions during the observed period.

5 For the cross-section model discussed in FAHRLÄNDER (2006 and 2007) information concerning the condition of the property at the point of the transaction is known. For transactions before 1999, this information is not available. Therefore, the index construction is based on rather new properties and the information on the condition therefore derivable from the year of construction.

6 Due to a very small number of observations, in some rural regions some earlier transactions from 1983 and 1984 have to be used in the cross-section models for 1985.

7 Alternative Bank Schweiz, Banque Cantonale Vaudoise, Helvetia Patria Versicherungsgesellschaft, Luzerner Kantonalbank, Thurgauer Kantonalbank, UBS, Zürcher Kantonalbank, Zurich Financial Services. 
The data pool can be divided into objects with their own identifiable site area (single family houses) and objects without their own site area (condominiums). The latter include terraced apartments and other special cases. Prices from arm's length transactions only are included in the samples. Special cases like ground leases, objects with depreciating easements or big development reserves are excluded, as well as properties with extreme characteristics. This is to avoid problems with leverage points.

Besides the date and price of the transaction, important characteristics of the properties are available (Table 1).

For the size of the properties the dwelling in $\mathrm{m}^{2}$ is used for condominiums, for single family houses the cubic content in $\mathrm{m}^{3}$ and the size of the site in $\mathrm{m}^{2}$ are available. Due to non-divisibility, site areas in Switzerland are often larger than necessary for a certain cubic content of a single family house. Using assumptions for regionally differentiated planning and construction laws, the sites can be split into necessary and additional site area. ${ }^{8}$ In addition the construction year and a rather rough assessment of the standard of the properties are available.

Since no geo-coordinates are available, the postal code is used to define the village or the district in the major cities. ${ }^{9}$ In addition to the village, a rather rough assessment of the location within the village (micro-location), assessed by the data providing companies, is compiled as well. ${ }^{10}$

Except for the data of the Zürcher Kantonalbank the data was compiled in the years 1999 and later, meaning that all the compiled characteristics concern this specific period and not the time of the transaction. Therefore, it has to be assumed that the characteristics at the time of the compilation are the same as they were at the time of the transaction. If in some cases this assumption should not hold, due to robust estimation the models should not be affected but the variance could slightly increase. Comparisons of the data and results of the subsample of the

8 In Switzerland planning law differs from Canton to Canton, in some Cantons even from political community to political community.

9 Some political communities consist of different villages of completely different attractiveness. The community of Lauterbrunnen in the Bernese Oberland for example consists of the village of Lauterbrunnen in the bottom of the valley as well as of the important tourist resorts Mürren and Wengen where prices are much higher than down in the valley. Therefore, price levels for villages should be considered instead of price levels of political communities. Out of 2780 political communities (as of December 2004) 2910 villages and city districts can be identified.

10 The micro-location is compiled as a indicator variable with five levels representing a weighted average of characteristics like exposition, view, quality of the neighbourhood, proximity to services and public transport and nuisances such as noise. 
Table 1: Variables

\begin{tabular}{lcc}
\hline & $\begin{array}{c}\text { Condominiums } \\
\text { Median 2004 }\end{array}$ & $\begin{array}{c}\text { Single family houses } \\
\text { Median 2004 }\end{array}$ \\
\hline Date of acquisition: yearqu & $1^{\text {st }}$ quarter 2004 & $2^{\text {nd }}$ quarter 2004 \\
Total sale price (in CHF, arm's length transactions) & 522000 & 710000 \\
Micro-location (factor with 5 levels): micro & 4 & 4 \\
Cubic content (in $\mathrm{m}^{3}$ SIA 416) v volsia03 $_{\text {Site area (in } \mathrm{m}^{2} \text { ): land }}$ & n.a. & 754 \\
Additional site area (in $\mathrm{m}^{2}$ ): landexc & n.a. & 511 \\
Dwelling area (in $\mathrm{m}^{2}$ SIA 416): nwf & n.a. & 100 \\
Construction year: bauj & 115 & n.a. \\
Standard (factor with 5 levels): stand & 2003 & 1996 \\
Detached / attached (indicator variable): att & 4 & 3 \\
N (1985-2004) & n.a. & detached \\
\hline
\end{tabular}

Source: Data Pool. For details see Fahrländer (2006 and 2007).

a See SIA (2003).

Zürcher Kantonalbank whose data were all compiled at the time of the transaction show that most characteristics do generally not change over a long period. The crucial variable in this context is the condition of the properties. Since renovation cycles are long, the variance does not increase for about thirty years of age of the properties despite the absence of an assessment of the condition of the properties at the time of the transaction. To maximize the size of the information to be used while minimizing the bias caused by the lack of information concerning the condition, condominiums and single family houses, which at the point of the transaction were thirty years old or newer, are included in the samples.

A total of 38803 transactions of condominiums and 30870 transactions of single family houses of the period January 1985 to December 2004 are included in this analysis (see Table 2 and 3 for the sample sizes). Centred moving samples over six quarters are generally used for the estimation of the annual regression models. ${ }^{11}$

11 Since for some of the earlier years, only a small number of observations are available, samples over three year periods become necessary in some rural regions in the periods before 1999 . 
Table 2: Annual Samples Condominiums

\begin{tabular}{|c|c|c|c|c|c|}
\hline Year & $\mathrm{N}$ & Sum transaction prices & Mean price & Median price & Stand. dev. \\
\hline 1985 & 589 & 207798071 & 352798 & 320000 & 188783 \\
\hline 1986 & 696 & 250940560 & 360547 & 330000 & 183579 \\
\hline 1987 & 794 & 304110541 & 383011 & 350000 & 190535 \\
\hline 1988 & 875 & 367474108 & 419970 & 390000 & 214385 \\
\hline 1989 & 909 & 421676323 & 463890 & 425000 & 240165 \\
\hline 1990 & 959 & 478830684 & 499302 & 459600 & 251203 \\
\hline 1991 & 1072 & 548456792 & 511620 & 475000 & 234344 \\
\hline 1992 & 1805 & 927339818 & 513762 & 484000 & 222636 \\
\hline 1993 & 2527 & 1324500563 & 524140 & 494546 & 224848 \\
\hline 1994 & 3284 & 1722437805 & 524494 & 500000 & 215332 \\
\hline 1995 & 3325 & 1742158893 & 523958 & 500000 & 208723 \\
\hline 1996 & 3393 & 1737234903 & 512006 & 495000 & 209025 \\
\hline 1997 & 3227 & 1631136249 & 505465 & 480000 & 220547 \\
\hline 1998 & 3488 & 1738891491 & 498535 & 474750 & 223115 \\
\hline 1999 & 4998 & 2496621470 & 499524 & 475000 & 220336 \\
\hline 2000 & 3806 & 2038141052 & 535507 & 493000 & 265063 \\
\hline 2001 & 6235 & 3463848722 & 555549 & 500000 & 335437 \\
\hline 2002 & 7616 & 4166039867 & 547012 & 493750 & 330260 \\
\hline 2003 & 12284 & 6950105783 & 565785 & 500000 & 338664 \\
\hline 2004 & 10549 & 6264741575 & 593871 & 522000 & 356705 \\
\hline
\end{tabular}

All prices in CHF.

Source: Data pool. 
Table 3: Annual Samples Single Family Houses

\begin{tabular}{|c|c|c|c|c|c|}
\hline Year & $\mathrm{N}$ & Sum transaction prices & Mean price & Median price & Stand. dev. \\
\hline 1985 & 685 & 428222211 & 625142 & 550000 & 333822 \\
\hline 1986 & 778 & 510261977 & 655864 & 590000 & 334590 \\
\hline 1987 & 856 & 580874413 & 678592 & 604000 & 333905 \\
\hline 1988 & 929 & 683715425 & 735969 & 669000 & 391731 \\
\hline 1989 & 949 & 756981398 & 797662 & 720000 & 425113 \\
\hline 1990 & 936 & 806784288 & 861949 & 770000 & 453555 \\
\hline 1991 & 952 & 818970044 & 860263 & 775000 & 397952 \\
\hline 1992 & 1327 & 1102079411 & 830504 & 760000 & 351746 \\
\hline 1993 & 1766 & 1461919776 & 827814 & 741000 & 869993 \\
\hline 1994 & 2182 & 1782675638 & 816992 & 740000 & 789561 \\
\hline 1995 & 2228 & 1790867650 & 803801 & 720000 & 783856 \\
\hline 1996 & 2356 & 1801063799 & 764458 & 700000 & 307132 \\
\hline 1997 & 2554 & 1902646189 & 744967 & 680000 & 311529 \\
\hline 1998 & 3082 & 2326009283 & 754708 & 685000 & 375111 \\
\hline 1999 & 4958 & 3883722515 & 783324 & 710000 & 383675 \\
\hline 2000 & 3802 & 3197124652 & 840906 & 750000 & 443505 \\
\hline 2001 & 5683 & 4891651184 & 860752 & 740000 & 873783 \\
\hline 2002 & 5441 & 4328324859 & 795502 & 700000 & 803774 \\
\hline 2003 & 8157 & 6388221157 & 783158 & 700000 & 389698 \\
\hline 2004 & 7353 & 5944122678 & 808394 & 710109 & 439242 \\
\hline
\end{tabular}

All prices in CHF.

Source: Data pool. 


\section{Models and Results}

\subsection{Setup}

The general setup is log-linear models with piecewise linear and quadratic terms for the continuous variables and factors for characteristics like the micro-location and the standard. ${ }^{12}$ The models have the general form

$$
\ln (\text { price })=\beta_{0}+f(X, \beta)+\varepsilon,
$$

with a vector of logarithms of the transaction prices $\ln$ (price), a matrix of characteristics $\mathrm{X}$, a vector of coefficients $\beta$ and a vector of disturbances $\varepsilon$.

In the model for the year 2004 price levels for the villages are estimated using fixed effects as well as a nearest-neighbour model for modelling the price level of villages without sufficient observations. ${ }^{13}$ Due to lack of data, this method is not applicable for the early years of observation. Therefore the estimated price levels of 2004 remain as a vector of the matrix X in the cross-section models of each of the earlier years but the general price level of regions is corrected. This implies that the structure of the "attractiveness of the villages" remains constant within the regions but varies between the regions. A factor can be applied estimating fixed effects $\beta_{i}$ for 40 regions and $\beta_{j}$ for the quarter of the transaction. Therefore for the period 1985 to 1999 the models are enlarged to

$$
\ln (\text { price })=\beta_{0}+\beta_{i}+\beta_{j}+f\left(X, \beta_{k}\right)+\varepsilon,
$$

where $\beta_{k}$ might vary from cross-section model to cross-section model. The 40 regions are defined in accordance with the availability of data. In the big urban areas Basel, Bern, Geneva, Lausanne or Zurich where many observations are available, regions are defined pooling only a small number of villages. In smaller urban areas such as Aarau, Lucerne, Lugano, Olten or St. Gallen a level can be generated

12 The setup is in accordance with the earlier discussion of non-linearities and regional differences of the continuous variables as well as interactions between variables (see FAHrLÄNDER, 2006 and 2007) For details also see appendix A and B.

13 The estimated macro-locations 2004 for all villages are based on a generalized additive model using thin plate regression splines on a system of coordinates based on driving times as well as the level of income taxation and some structural variables (see Hastie and Tibshirani, 1990 or Hastie, Tibshirani and Friedman, 2001). The used system of coordinates is based on a matrix of driving times between the villages. It consists of three principal coordinates calculated with metric multidimensional scaling (see Cox and Cox, 1994). 
for the urban area itself. In rural areas, where markets are thin and only little observations are available, some of the regions cover dozens of small villages.

For the period 2000 to 2004 due to the bigger number of observations the model is slightly different: Instead of a quarterly effect for the whole country, a quarterly effect $\beta_{i j}$ can be estimated for each of the forty regions, hence

$$
\ln (\text { price })=\beta_{0}+\beta_{i j}+f\left(X, \beta_{k}\right)+\varepsilon .
$$

Due to the elimination of leverage points like farmhouses with huge site areas or some cases with obviously wrong input data, the estimations should not be susceptible to such problems. However there is still a risk of outliers which especially in regions with little data available might have a very strong influence. Therefore robust techniques are applied for all estimations using Huber-M-estimators. ${ }^{14}$

\subsection{Statistical Results}

The analysis of the statistical results shows that the setup generally allows good results, despite the decrease of the standard errors (see Figure 1). The standard error of the regression for condominiums CON (Figure 1; upper black line) decreased from 0.2 in the late 1980 s to 0.12 by 2004 . This decrease of the standard error can be explained by the dramatic increase in the degrees of freedom during this period (Figure 1; dotted black line). The development of the respective numbers for single family houses SFH is comparable, though the standard errors are lower during most of the observed period. But still some part of the higher standard errors in the early years might have to be explained by the fixed structure of the price levels of the villages within the regions. This assumption affects all regions since the analysis of the residuals against the regions and even the villages show no striking structures such as higher variance in larger regions or other. The constant variance across the villages speaks against the thesis of massive insufficient consideration of the price levels of the villages. It is far more likely that major refurbishments and changes in size and standard of some of the properties between the time of the transaction and the time of the compilation of the data contributed to the bigger variances in the late 1980s.

Despite the lack of information concerning the earlier transactions and possible variations in the structure of the price levels of the villages within the regions we believe that the chosen setup generates usable results over the whole observed period.

14 On robust methods see for example Hampel et al. (1986) or Rousseeuw and Leroy (2003). 
Figure 1: Standard Errors (S.E.) and Degrees of Freedom (D.F.)

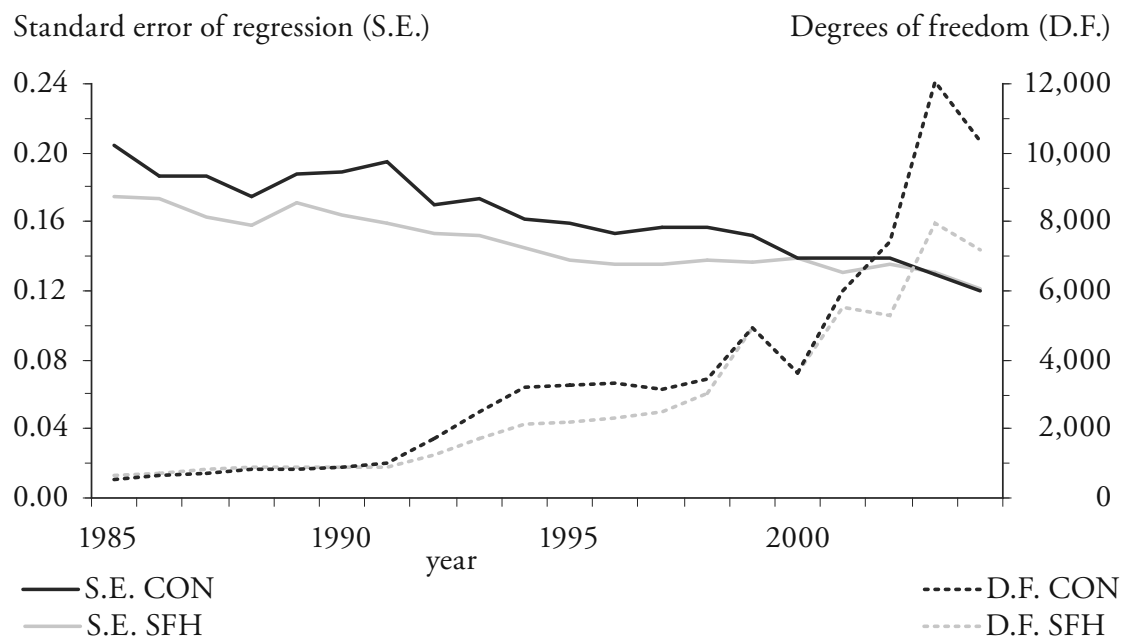

Based on the yearly equations, the estimated coefficients show strong changes in the hedonic prices in the dynamic view, both for condominiums and single family houses. The coefficients for the dwelling (Figure 2) and for the factor standard (Figure 3) for example show strong changes of the hedonic prices over the period observed. This indicates that constant hedonic prices, as usually used in the direct method, are too strong an assumption and indexes of non-average properties are biased when based on the direct method. The fact that the coefficients do not just decrease going back to the year 1985 and the generally high significance suggest that these changes in the hedonic prices are not just artefacts because of decreasing quality of the data. However, some questions remain unanswered like for example the fact, that for the year 1985 the estimated coefficient for an excellent standard (see Figure 3, stand $=5$ ) is smaller than the coefficient for an elevated standard (stand =4). This seems not to be very likely and is a hint for insufficient data quantity and quality in the early years of observation. ${ }^{15}$

Overall, most of the coefficients in the yearly equations are highly significant and they show the expected direction. This leads to the conclusion, that the models with their assumptions render good results.

15 Since the micro-location and the standard of the properties are highly correlated, this effect could be compensated by the coefficient for excellent micro-location. 
Figure 2: Selected Yearly Slopes for Segments of $\ln (\mathrm{nwf})$

\section{Coefficient}

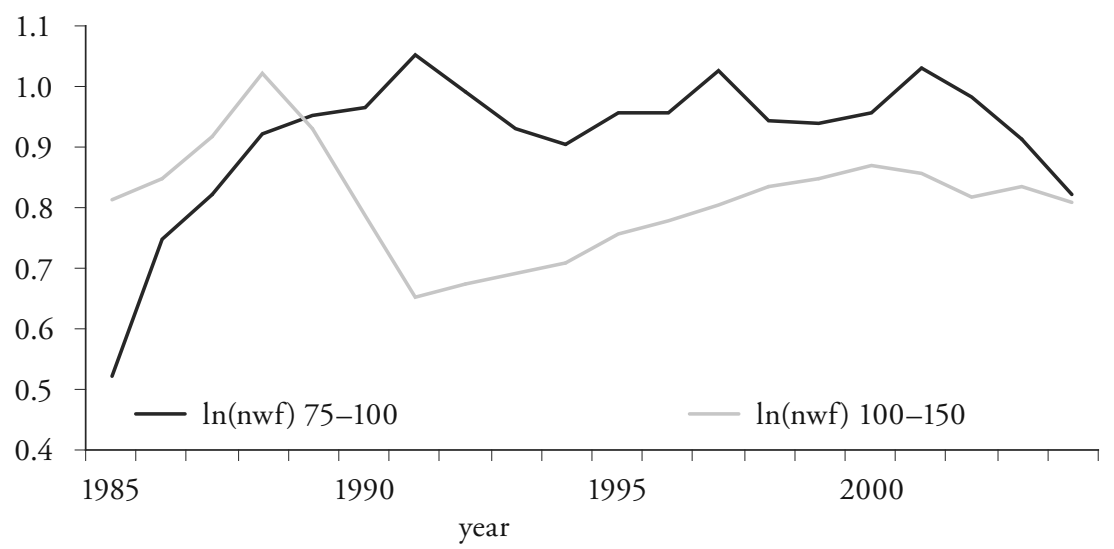

Note: $\ln (\mathrm{nwf})$ is the logarithm of the dwelling area of condominiums. The coefficient for the dwelling area is divided into five piecewise log-linear terms (see FAHRLÄNDER, 2006 and 2007). $\ln$ (nwf) $75-100$ is the slope for condominiums with a dwelling area of more than 75 square meters and at most 100 square meters.

Figure 3: Yearly Coefficients for Condition 4 and 5 for Condominiums

\section{Coefficient}

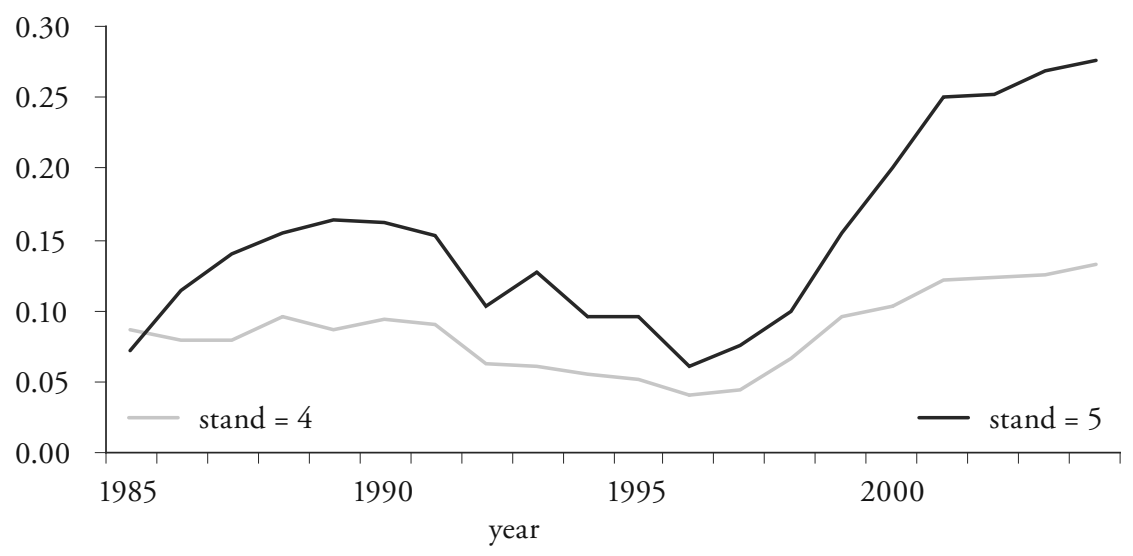

Note: The first level (omitted) is average (stand $=3$ ). Stand $=4$ represents an elevated standard, stand $=5$ a luxurious standard of the condominiums. 
The question remains if the observed changes in the coefficients are significant, i.e. if the structure of the model changes from a statistical point of view. This question can not be answered by just considering the coefficients one by one. Statistically the question of structural change of the model can be answered using the Chow-test (see for example Greene, 1997, pp. $349 \mathrm{ff}$.).

The test-statistic is calculated as

$$
\text { Chow }=\frac{\left(S S R_{12}-S S R_{1}-S S R_{2}\right) / m}{\left(S S R_{1}+S S R_{2}\right) /\left(N_{1}+N_{2}-2 m\right)} \approx F\left(m, N_{1}+N_{2}-m\right)
$$

with $S S R_{12}=$ sum of squares of the residuals in a pooled model, $S S R_{1}=$ sum of squares of residuals in the equation for year $1, S S R_{2}=$ sum of squares of residuals in the equation for year 2, $m=$ number of coefficients, and $N_{1}$ and $N_{2}=$ number of observations in the equations for years 1 and 2 . The resulting test-statistic has an $F$-distribution with $m$ and $\left(N_{1}+N_{2}-m\right)$ degrees of freedom. With regard to the big number of observations, the critical value for the rejection of the hypothesis that the coefficients are equal on a $95 \%$ level is 1.32 .

The yearly equations can be compared pairwise in order to identify the length of a period during which structural changes are not significant, i.e. direct indexes could be estimated (see Table 4). The comparison of the annual equations with the equation 1998 shows test-statistics of 0.39 and 0.03 , indicating that a pooling with the years 1997 and 1999 would not result in a much larger sum of squares of the residuals. But this short view is already influenced by the fact that one third of the samples are identical in each of the two equations. The comparison of the year 1998 with the year 1996 leads to a test-statistic of 1.98, which makes us reject the hypothesis that there is no structural change on a $95 \%$ significance level. ${ }^{16}$

In general the results show that a pooling of the data over a certain period should usually not lead to a dramatic increase in the sum of squares of residuals. But for an extended period of observation, the model should be split into different equations, and indirect indexes should be constructed. Results are comparable for both condominiums and single family houses.

Using the annual equations, predictions for specific objects $x^{0}$ can be calculated and the resulting market values can be indexed.

16 These tests have been calculated for all years and show a comparable pattern as shown for the years 1998 and 1999 in Table 4. 
Table 4: Statistics of the Pair Wise Chow-Tests for Condominiums

\begin{tabular}{lcccccccccccccc}
\hline year & 1985 & '86 & '87 & '88 & '89 & '90 & '91 & '92 & '93 & '94 & '95 & '96 & '97 & '98 \\
\hline 1998 & 2.16 & 2.18 & 2.64 & 3.35 & 2.93 & 2.68 & 2.91 & 3.22 & 3.17 & 3.71 & 3.30 & 1.98 & 0.39 & \\
1999 & 2.44 & 2.42 & 2.91 & 3.59 & 3.24 & 3.13 & 3.39 & 4.48 & 4.29 & 5.51 & 4.98 & 3.97 & 1.86 & 0.03 \\
\hline
\end{tabular}

The quarterly indexation results in good but quite rough indexes and the quarterly values are mainly interesting to identify turning points and other specific effects. For an analysis of the price paths, the indexes could be smoothed by using annual averages. To still be able to show turning points without using unnecessary complex methods, it seems to be reasonable, to smooth the indexes using annual means or a centred moving average over the length of five quarters (see Figure 4).

Figure 4: Smoothed Index for an Average Condominium 1st Qarter 1985 to 4th Quarter 2004

Index $(1985=100)$

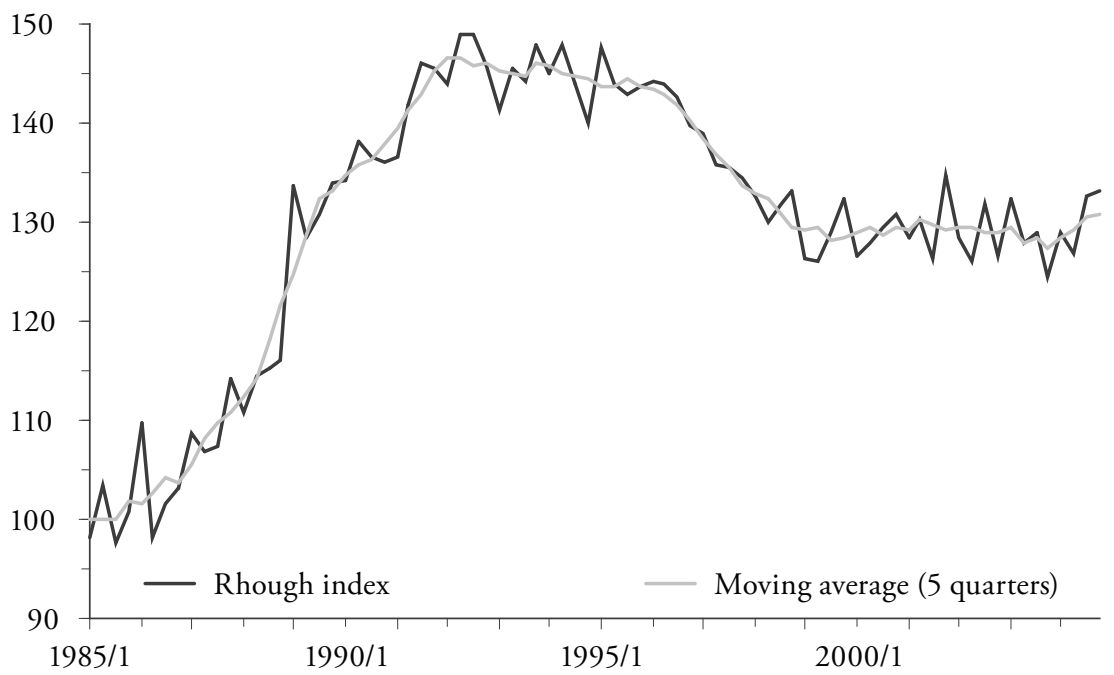




\subsection{Considering Ageing and Refurbishments}

Due to changes in the coefficients over the observed periods, indexes for properties with different specification can vary (see Figure 5). ${ }^{17}$ The price path for two, otherwise identical, condominiums with different size show the same total change between 1985 and 1991 but the decrease of the value during the 1990s is much stronger for the small apartment in comparison to the bigger one.

Figure 5: Indexes for Otherwise Identical Condominiums of Different Size 1985 to 2004

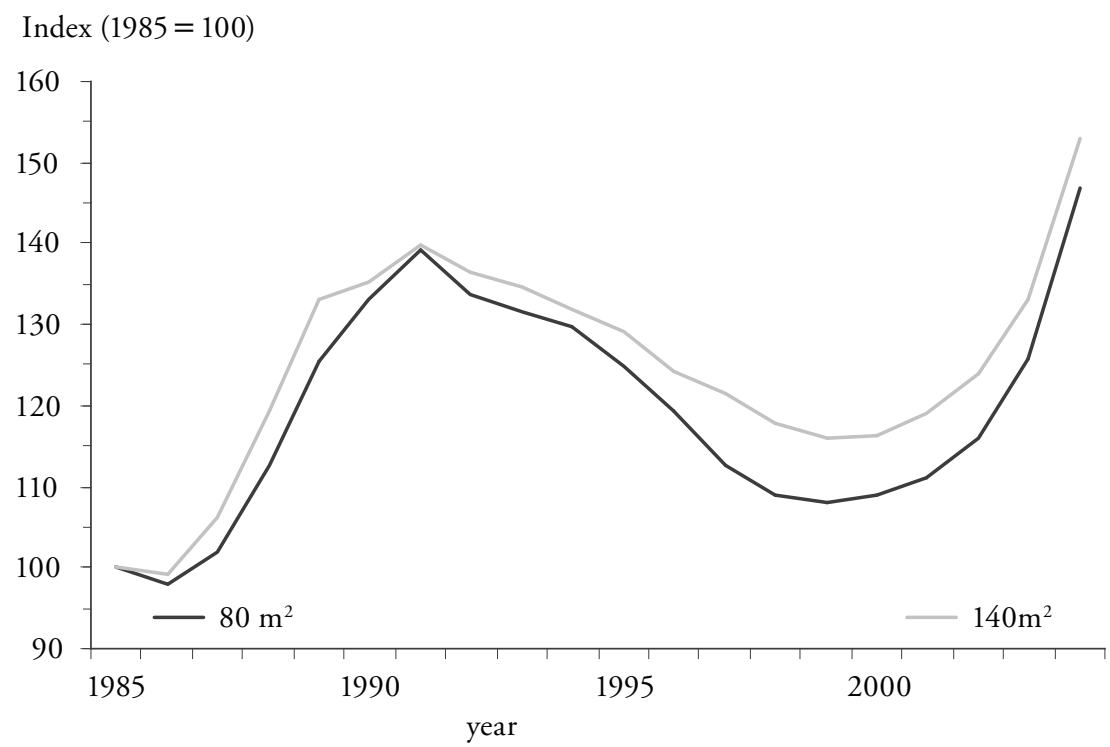

These differences might be bigger or smaller depending on the region and the specification of the properties.

As the condition of properties without refurbishments decreases with age, their market value decreases as well because buyers do consider the costs for the refurbishment of an old property. In this market view, for the shown example,

17 Condominium with average standard and good location within Küsnacht $\mathrm{ZH}$, constructed in 1985. 
refurbishment must not cost more than $200000 \mathrm{CHF}$ which is equivalent to an approximate annual decrease of $1 \%$ of the 2004 market value. If the estimated costs for refurbishment are higher, a buyer better goes for a new apartment or tries to negotiate the price.

Figure 6: Old versus New: Average Condominium with Refurbishment in 1998

CHF x 1,000

Index $(1985=100)$

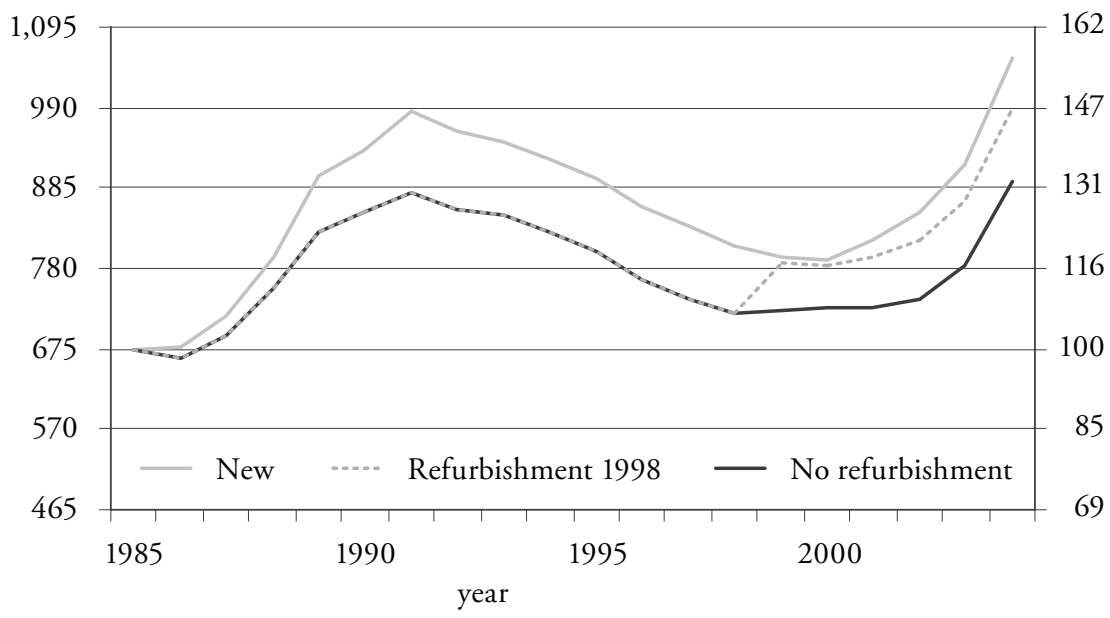

For the practical indexation of properties, it seems absolutely crucial, that refurbishments are considered (see Figure 6) since they can alter the value of the property dramatically.

Depending on the purpose, both types of indexes are useful. To answer the question of the price path of an apartment that in 1985 was newly constructed but not refurbished, the lower line gives the path and today's value. The upper line represents the price path of an always identical, i.e. always new, apartment. The difference between the two price paths can be interpreted as a market view of the necessary refurbishment, thus indicating whether or not investing in an old property is a good idea. 


\subsection{Regional Dynamics}

The models allow the indexation of a large variety of properties with different specifications, especially with regard to the region. In principle indexes could be constructed for almost every existing private property in Switzerland. For the purpose of market analysis nationwide charts of index changes of identical objects throughout Switzerland are useful. Figures 7 and 8 for example show the index changes between the annual means of 2001 and 2004 for standard condominiums and single family houses.

The map for condominiums (Figure 7) shows, that prices in this market segment increased in almost all urban and tourist areas especially in the Bassin Lémanique, in the Lugano area in Southern Switzerland, in the triangle ZurichZug-Lucerne and in the tourist hot spots. Declines are observed in rural regions like the Jura and Southern Switzerland as well as in some smaller urban and semiurban areas in the "Mittelland".

Figure 7: Change in \% of the Values of Typical Condominiums 2001 to 2004

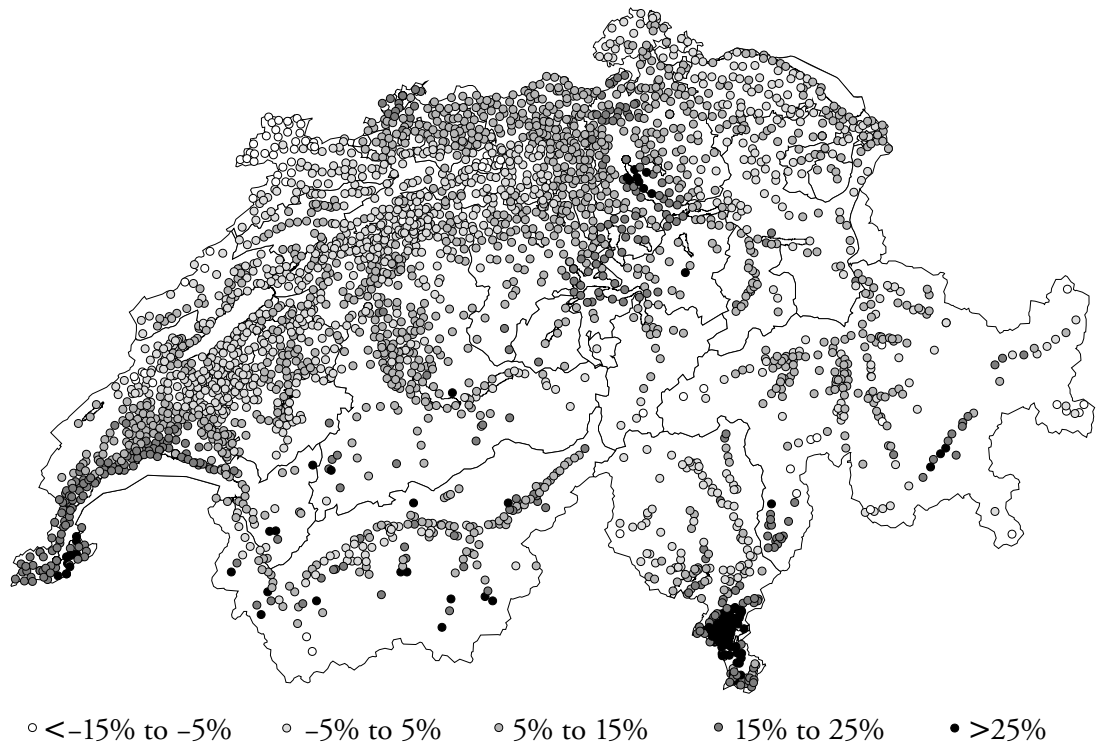

Due to large reserves of construction sites in less urban regions, single family houses generally show quite constant nominal prices in the observed period (see 
ARE, 2005, p. 33). Exceptions are again the Bassin Lémanique, the triangle Zurich-Zug-Lucerne as well as the Lugano area and the tourist centres where construction sites are quite rare and demand is high (Figure 8).

Figure 8: Change in Percent of the Values of Typical Single Family Houses 2001 to 2004

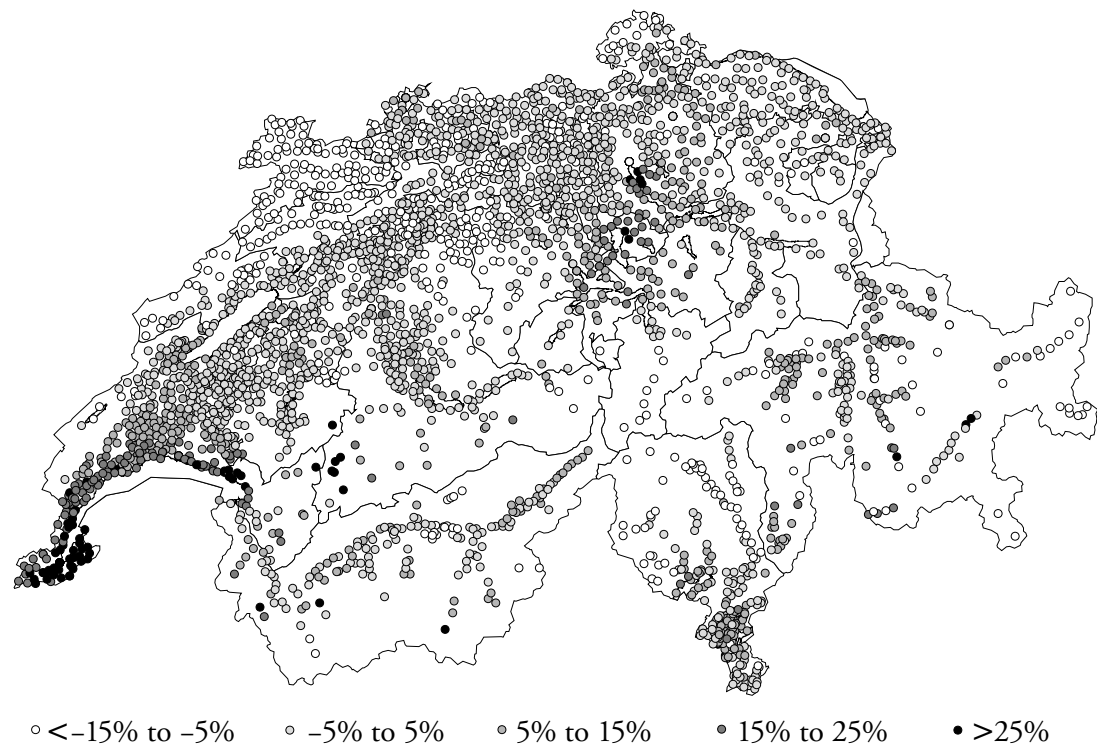

Lately, the observed increases in prices in the mentioned areas are discussed by the public and warnings of a "price bubble" in these regional markets are heard (see for example NZZ, 2005). In 2004 prices in most regions were - in nominal terms - still about equal or lower to the last Swiss real estate peak at the end of the 1980s, as Figure 9 shows for condominiums and Figure 10 shows for single family houses. Also for regions, where prices today are higher than during the last peak, the question remains, if these new levels are sustainable or not. With regard to the change in the consumer prices of about $25 \%$ between 1990 and 2004 only very few villages show an increase of real property values during this period. 
Figure 9: Values of Typical Condominiums in 2004 versus the Values around 1990

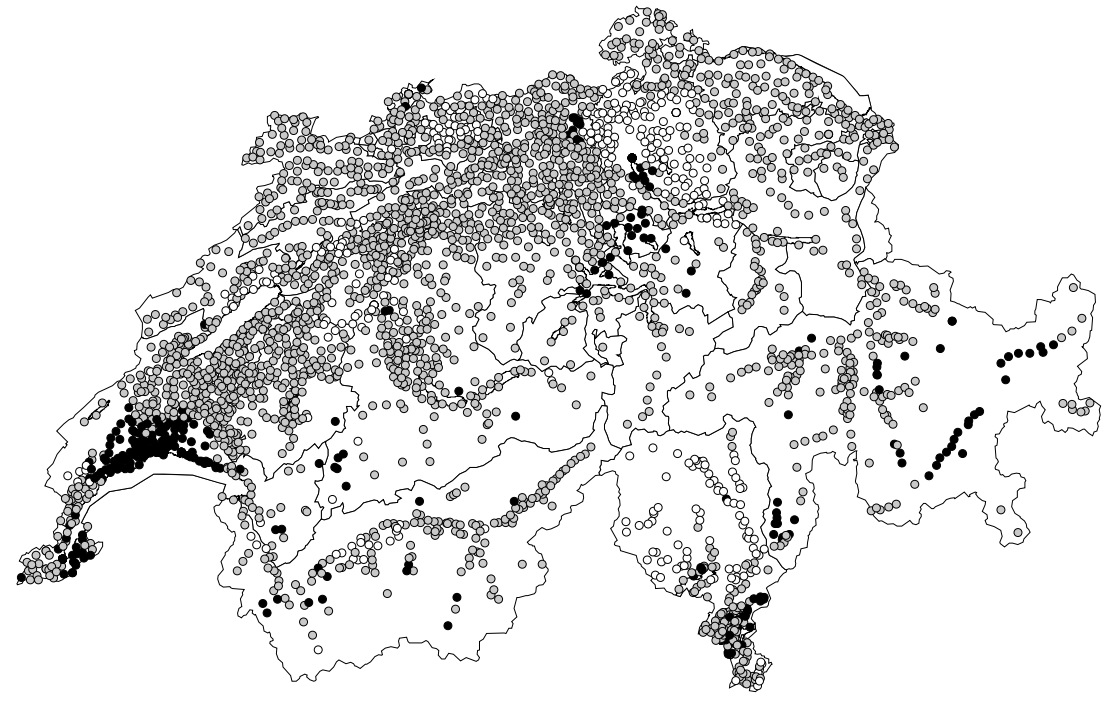

- less than around 1990

- equal to around 1990

- greater than around 1990

Figure 10: Values of Typical Single Family Houses in 2004 versus the Values around 1990

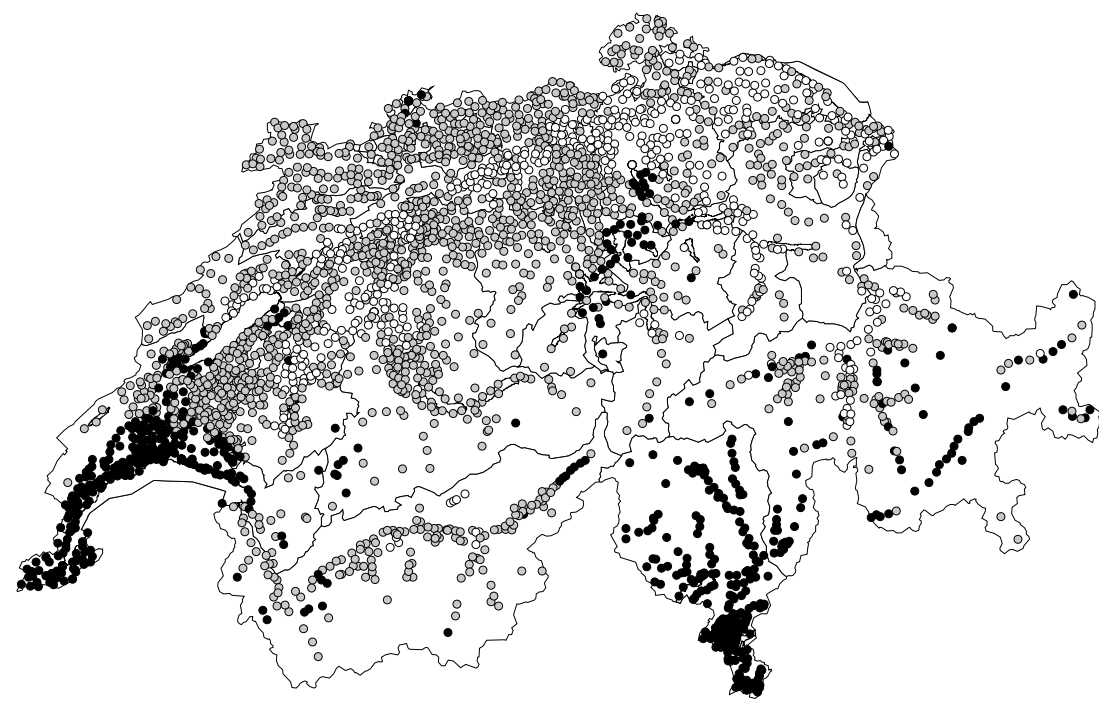

- less than around 1990

- equal to around 1990

- greater than around 1990 


\section{Concluding Remarks}

In this article we show, that the direct construction of price indexes for private properties is inferior to the indirect construction, since hedonic prices usually change over time. On a short view, direct indexes might be necessary due to small sample sizes and they should not lead to a major bias. But with regard to business cycles as well as possible changes of the preferences, structural changes in the models should be considered. Using indirectly constructed indexes, it can be demonstrated that two properties that are identical except for one characteristic show quite different price paths in the long run.

From the point of view of regional dynamics, regions show different price paths. In general, in urban areas, where construction sites are rare, prices are much more volatile and probably also more sensitive to business cycles, changes in mortgage costs and general trends than in rural regions where plenty of new construction sites are available. In such regions sellers of second hand properties might have to accept bigger discounts in the future due to emigration and an ageing society.

Regionally differentiated specific indexes are a powerful tool for real estate market analysis and due to the fact, that they are based purely on observed transactions but no other regional input data, they may serve as input for other regional models. The indirect setup allowing hedonic prices to change over time allows the construction of more complex aggregated indexes using baskets of different properties for example as sub-index of the CPI or other constructs depending on the purpose of the index. ${ }^{18}$

However, for the earlier years of the observed period, data is rather scarce so further improvements of the models and their regional differentiation might be possible if more observations and more detailed data were available.

18 On aggregated indexes see for example TöRnQvist (1936), Boskin et al. (1996) or BRACHINGer, SChips and STIER (1999). 


\section{Appendix}

Table A: Robust Estimation Output for Condominiums 2004

\begin{tabular}{|c|c|c|c|}
\hline & Coefficient & Standard error & Sign. level \\
\hline Intercept & 373.055 & 72.764 & $* * *$ \\
\hline macro & 0.948 & 0.008 & $* * *$ \\
\hline DNWF50 & -1.272 & 0.152 & $* * *$ \\
\hline LNWF50 & 1.114 & 0.035 & $* * *$ \\
\hline DNWF5075 & -0.352 & 0.164 & $* *$ \\
\hline LNWF5075 & 0.881 & 0.034 & $* * *$ \\
\hline DNWF7500 & -0.056 & 0.179 & n.s. \\
\hline LNWF7500 & 0.820 & 0.036 & $* * *$ \\
\hline LNWF0150 & 0.810 & 0.017 & $* * *$ \\
\hline DNWF150P & -0.442 & 0.146 & $* * *$ \\
\hline LNWF150P & 0.899 & 0.024 & $* * *$ \\
\hline bauj & -0.652 & 0.073 & $* * *$ \\
\hline bauj $^{2}$ & 0.000 & 0.000 & $* * *$ \\
\hline stand: 4 & 0.132 & 0.003 & $* * *$ \\
\hline stand: 5 & 0.276 & 0.006 & $* * *$ \\
\hline micro: 4 & 0.119 & 0.003 & $* * *$ \\
\hline micro: 5 & 0.283 & 0.005 & $* * *$ \\
\hline S.E. residuals & 0.120 & & \\
\hline D.F. residuals & 10345 & & \\
\hline $\mathrm{R}^{2 \mathrm{~b}}$ & 0.965 & & \\
\hline
\end{tabular}

Note: “.” represents a significance level of $10 \%,{ }^{*}$ a $5 \%,{ }^{* *}$ a $1 \%$ and ${ }^{* * *}$ a $1 \%$ o significance level. DNWF50 is the dummy for condominiums with a dwelling up to $50 \mathrm{~m}^{2}$, LNWF50 the respective slope. Also see table 1 .

a For practical reasons, the quarterly coefficients for the regions are not shown.

b The robust $\mathrm{R}^{2}$ is calculated as proposed by RousseEuw and Leroy (1987). 
Table B: Robust Estimation Output for Single Family Houses $2004^{a}$

\begin{tabular}{|c|c|c|c|}
\hline & Coefficient & Standard error & Sign. level \\
\hline Intercept & 10.194 & 86.720 & n.s. \\
\hline macro & 0.892 & 0.010 & $* * *$ \\
\hline DVOL600 & -1.566 & 0.144 & $* * *$ \\
\hline LVOL600 & 0.747 & 0.023 & $* * *$ \\
\hline LVOL1300 & 0.507 & 0.004 & $* * *$ \\
\hline DVOL2300 & -0.760 & 0.373 & * \\
\hline LVOL2300 & 0.627 & 0.051 & $* * *$ \\
\hline LLA2000 & 0.002 & 0.002 & n.s. \\
\hline LLAE250 & 0.021 & 0.001 & $* * *$ \\
\hline DLAE600 & -0.301 & 0.085 & $* * *$ \\
\hline LLAE600 & 0.077 & 0.014 & $* * *$ \\
\hline DLAE1800 & 0.055 & 0.126 & n.s. \\
\hline LLAE1800 & 0.023 & 0.019 & n.s. \\
\hline bauj & -0.146 & 0.087 & . \\
\hline bauj $^{2}$ & 0.000 & 0.000 & . \\
\hline stand: 4 & 0.123 & 0.004 & $* * *$ \\
\hline stand: 5 & 0.215 & 0.007 & $* * *$ \\
\hline micro: 4 & 0.109 & 0.004 & $* * *$ \\
\hline micro: 5 & 0.289 & 0.006 & $* * *$ \\
\hline S.E. residuals & 0.121 & & \\
\hline D.F. residuals & 7163 & & \\
\hline $\mathrm{R}^{2 \mathrm{~b}}$ & 0.937 & & \\
\hline
\end{tabular}

Note: “.” represents a significance level of $10 \%,{ }^{*}$ a $5 \%,{ }^{* *}$ a $1 \%$ and ${ }^{* * *}$ a $1 \%$ o significance level. DVOL600 is the dummy for single family houses with a cubic content up to $600 \mathrm{~m}^{3}$, LVOL600 the respective slope. Also see table 1.

a For practical reasons, the quarterly coefficients for the regions are not shown.

b The robust $\mathrm{R}^{2}$ is calculated as proposed by Rousseeuw and Leroy (1987). 


\section{References}

ARE (2005), Raumentwicklungsbericht 2005, Ed.: Eidgenössisches Departement für Umwelt, Verkehr, Energie und Kommunikation; Bundesamt für Raumentwicklung, Bern.

BAK \& FPRE (2007), Wohnimmobilien 2007-2022, Ed.: BAK Basel Economics and Fahrländer Partner, Basel, Zürich.

Bender, A. R., B. Gacem and M. Hoesli (1994), "Construction d'indices immobiliers selon l'approche hédoniste», in Finanzmarkt und Portfoliomanagement, vol. 8, no. 4, pp. 522-533.

BignasCa, F., et al. (1996), Immobilienmarkt Zürich: Immobilienpreise und Bauinvestitionen unter der Lupe, Ed.: Zürcher Kantonalbank, Zürich.

Boskin, Michael J., et al. (1996), (Advisory Commission To Study The Consumer Price Index); Toward a More Accurate Measure of the Cost of Living: Final Report to the Senate Finance Commission, Washington.

Brachinger, H. W., B. Schips and W. Stier (1999), „Revision Landesindex 2000: Expertise zur Relevanz des Boskin-Reports für den schweizerischen Landesindex der Konsumentenpreise“, in BFS aktuell, Neuchâtel.

Cox, T. F., and M. A. A. Cox (1994), Multidimensional Scaling, Monographs on Statistics and Applied Probability 59, London.

FAHRLÄNDER, S. (2001a), „Hedonische Handänderungspreisindizes: Konzeption und Methodik“, Ed. Wüest \& Partner, Zürich (mimeo).

FAhrläNDER, S. (2001b), „Performance von Wohneigentum“, in Immo-Monitoring 2002, Band I, Wohnungsmarkt, Ed.: Wüest \& Partner, Zürich.

Fahrländer, S. and U. Hausmann (2001), „Ronco ist nicht Zug, Zug ist nicht Genf: Grosse Unterschiede in der regionalen Wertentwicklung von Wohneigentum“, in Neue Zürcher Zeitung, no. 151, Zürich.

FAHrLÄNDER, S. (2006), "Semiparametric Construction of Spatial Generalized Hedonic Models for Private Properties", in Swiss Journal of Economics and Statistics, vol. 142 (4), pp. 501-528.

FAHRLÄNDER, S. (2007), Hedonische Immobilienbewertung: Eine empirische Untersuchung der Schweizer Märkte für Wohneigentum 1985 bis 2005, München.

Greene, W. H. (1997), Econometric Analysis, 3rd edition, London etc.

Hampel F. R., et al. (1986), Robust Statistics: The Approach Based on Influence Functions, New York.

Hastie, T., and R. Tibshirani (1990), Generalized Additive Models, London. Hastie, T., R. Tibshirani and J. Friedman (2001), The Elements of Statistical Learning, New York. 
Hoesli, M., P. Favarger and C. Ciacotto (1997), "Real Estate Price Indices and Performance", in Swiss Journal of Economics and Statistics, vol.133, pp. 29-48.

Maurer, R., M. Pitzer and S. Sebastian (2000), Konstruktion transaktionsbasierter Immobilienpreisindizes: Theoretische Grundlagen und empirische Umsetzung für den Wohnungsmarkt in Paris, http://www.finance.uni-frankfurt.de.

Murray, J., and N. Sarantis (1999), "Price-Quality Relations and Hedonic Price Indexes for Cars in the United Kingdom", in International Journal of the Economics of Business, vol. 6, no. 1, pp. 5-27.

NZZ (2005), „Keine Immobilienblase in der Schweiz: Lokal deutliche Preissteigerungen bei Eigenheimen“, in Neue Zürcher Zeitung, Nr. 285, 6 december 2005, p. 25.

Rousseeuw, P. J., and A. M. Leroy (2003), Robust Regression and Outlier Detection, New York.

Salvi, M., P. Schellenbauer and H. Schmidt (2004), Preise, Mieten und Renditen: Der Immobilienmarkt transparent gemacht, Ed.: Zürcher Kantonalbank, Zürich.

Scognamiglio, D. (2000), Methoden zur Immobilienbewertung im Vergleich: Eine empirische Untersuchung für die Schweiz, Dissertation, Bern.

SIA (2003), Schweizer Norm 504 416: Flächen und Volumen von Gebäuden, Zürich.

Törnqvist, L. (1936), “The Bank of Finland's Consumption Price Index”, in Bank of Finland Monthly Bulletin, vol. 10, pp. 27-33.

Wolverton, M. L., and J. Senteza (2000), "Hedonic Estimates of Regional Constant Quarterly House Prices", in JRER, no. 3.

\section{SUMMARY}

This paper analyzes the construction of price indexes for condominiums and single family houses in Switzerland over the period 1985 to 2004 using the indirect method. We find, that the pooling of the data, i.e. direct indexes with fixed hedonic prices, are good models for average properties but can be biased for the indexation of non-average properties. Therefore indirect index construction using predictions for specific properties based on annual equations is recommended.

Based on differentiation of forty regions it is shown, that indexes vary from region to region, but show a comparable general path between 1985 and 2004 . In recent years prices for single family houses raised in the large urban areas and 
tourist resorts but, due to big land reserves, were stable or even declined in smaller urban and semi-urban as well as in rural areas. Price paths for condominiums are generally comparable to those of single family houses with the big difference, that over the last three years prices were raising in most of the regions. 